\title{
Alcohol-related brief intervention in patients treated for opiate or cocaine dependence: a randomized controlled study
}

\author{
Nelson Feldman*, Anne Chatton, Riaz Khan, Yasser Khazaal and Daniele Zullino
}

\begin{abstract}
Background: Despite the importance of heavy drinking and alcohol dependence among patients with opiate and cocaine dependence, few studies have evaluated specific interventions within this group. The aim of the present study was to evaluate the impact of screening with the Alcohol Use Disorders Identification Test (AUDIT) and of brief intervention (BI) on alcohol use in a sample of patients treated for opioid or cocaine dependence in a specialized outpatient clinic.

Methods: Adult outpatients treated for opioid or cocaine dependence in Switzerland were screened for excessive alcohol drinking and dependence with the AUDIT. Patients with AUDIT scores that indicated excessive drinking or dependence were randomized into two groups-treatment as usual or treatment as usual together with $\mathrm{Bl}$-and assessed at 3 months and 9 months.

Results: Findings revealed a high rate (44\%) of problematic alcohol use (excessive drinking and dependence) among patients with opiate and cocaine dependence. The number of drinks per week decreased significantly between T0 (inclusion) and T3 (month 3). A decrease in average AUDIT scores was observed between T0 and T3 and between T0 and T9 (month 9). No statistically significant difference between treatment groups was observed.

Conclusions: In a substance abuse specialized setting, screening for alcohol use with the AUDIT, followed by feedback on the score, and use of alcohol Bl are both possibly useful strategies to induce changes in problematic alcohol use. Definitive conclusions cannot, however, be drawn from the study because of limitations such as lack of a naturalistic group. An important result of the study is the excellent internal consistency of AUDIT in a population treated for opiate or cocaine dependence.
\end{abstract}

Keywords: AUDIT, brief intervention, alcohol, methadone, substance abuse

\section{Introduction}

Alcohol misuse and dependence is a major problem among opioid- and cocaine-dependent patients [1-4]. This association is linked to lower response to methadone substitution [3-5], more frequent overdose [6-9], lower quality of life [10], and higher risk of impulsive behaviors [11]. Alcohol consumption is common among cocaine users [12]. It can trigger cravings for cocaine and thus relapse $[12,13]$ and may reduce anxiety and dysphoria induced by cocaine withdrawal $[12,13]$, leading to alcohol use. This clinical evidence increases interest in specific alcohol interventions for patients with cocaine dependence. Despite the

\footnotetext{
* Correspondence: Nelson.feldman@hcuge.ch

Geneva University Hospitals, Geneva, Switzerland
}

importance of alcohol-related problem among patients with opiate and cocaine dependence, however, few studies have evaluated specific interventions within this group.

Brief intervention (BI) is one such intervention that could be of particular interest for its simplicity and accessibility. Among excessive drinkers who were treated in primary care settings, BI reduced the percentage of excessive drinking, the quantity and frequency of alcohol consumption, and the negative consequences associated with alcohol use [14-16]. These results were confirmed in settings such as emergency services [17] and practitioners' clinics [18], as well as in various adolescent populations [19]. In addition, positive results were published in the BRAINE study, a randomized

\section{()


clinical trial that evaluated BI in 197 intravenous drug users [2].

Several less favorable results have also been shown, however, in studies of alcohol-dependent patients [18,20], dual diagnosis patients [21], and patients in various other settings, such as emergency [22] and general hospitals [23]. These disparities among studies are possibly due to differences in the patient and setting characteristics.

Although the efficacy of BI in different settings remains controversial, it seems to be a simple and relatively efficient intervention $[24,25]$. The aim of the present randomized controlled study was to evaluate the impact of screening with the Alcohol Use Disorders Identification Test (AUDIT)[26]-a 10-item self-assessment questionnaire for alcohol abuse and dependence-and of BI on alcohol use among patients treated for opioid and cocaine dependence in a specialized outpatient clinic.

\section{Methods}

\section{Participants}

The study was carried out in the outpatient clinic of the division of substance abuse of the University Hospitals of Geneva. For 1 year, participation in the study was proposed systematically to each adult (age $\geq 18$ years) outpatient who was treated for opioid or cocaine dependence. Patients were excluded if they had an acute psychotic or manic episode, had a severe major depressive episode, patients did not understand the French language, were unable to give informed consent, or were already in treatment for problems related to alcohol misuse at the time of inclusion.

The study protocol was approved by the Geneva Ethics Committee. All participants received written information about the study and gave written informed consent.

\section{Measures}

The participants were assessed with the following instruments:

1. Alcohol Use Disorders Identification Test (AUDIT)

The AUDIT [26] is a 10-item self-assessment questionnaire that presents good sensitivity and specificity for the screening of excessive alcohol use and dependence [26-28]. The first three questions of the AUDIT assess frequency and quantity of alcohol use. AUDIT has been translated and validated in the French language [29]. According to the cutoff values in the French validation, three groups can be identified:

(a) abstinent patients or occasional nonproblematic drinkers (score $<7$ for men and $<6$ for women); (b) excessive drinkers $(7 \leq$ AUDIT score $<13$ for men and 6 $\leq$ AUDIT score $<13$ for women); and (c) alcohol dependents (score $>13$ ).

All screened patients received feedback that explained the meaning of their AUDIT score. All study participants were assessed with the AUDIT questionnaire at inclusion and those with excessive drinking or alcohol dependence were also assessed at 3 and 9 months. Diagnoses were established according to the criteria of the International Statistical Classification of Diseases and Related Health Problems, 10th revision (ICD-10) [30] by a resident and a senior psychiatrist.

2. Demographic and clinical characteristics collected at baseline

\section{Treatment allocation}

Patients identified as having excessive alcohol use or dependence (AUDIT scores $\geq 6$ for women or $\geq 7$ for men) were randomized to receive treatment as usual (control group) or treatment as usual plus BI (intervention group). The patients in both groups were already in treatment for opioid or cocaine dependence before study inclusion. The patients allocated to BI received this intervention 2 or 3 weeks after AUDIT screening (time to assign $\mathrm{BI}$ to the staff after randomization and to give the patient an appointment).

1. Brief intervention

A BI was dispensed between 1 and 3 weeks after the screening with the AUDIT questionnaire by specifically trained staff. The form in which BI was dispensed was similar to that described elsewhere $[14,25]$ and was based on the following principles and actions:

- Provide feedback to the patient about the result of the AUDIT questionnaire.

- Identify risks and discuss consequences.

- Display an emphatic and nonjudgmental attitude.

- Solicit the patient's commitment.

- Identify the goal: reduced drinking or abstinence.

- Propose a decrease in alcohol consumption with a choice of personal strategies.

- Emphasize personal responsibility for change and stimulate an attitude of change.

- Give advice and encouragement.

Promote self-observation in the consumption of alcohol.

BI was provided by a multidisciplinary team (psychiatrists, psychologists, nurses, and social workers) in the Division of Substance Abuse of the University Hospitals of Geneva. BI took 16 min with a standard deviation of 4.7. Training was provided during two workshops $(4 \mathrm{~h})$ by an expert in the field. He provided the staff with guidelines and information about the principles of BI.

\section{Control group}

The control group received treatment as usual in addition to AUDIT and score feedback. Treatment as usual refers to outpatient pharmacological and psychosocial treatment in the Division of Substance Abuse of the 
University Hospitals of Geneva. The outpatient staff is a multidisciplinary team: a psychiatrist, general practitioner, psychologist, nurse, and social worker.

Maintenance treatment with methadone or heroin includes medical and psychiatric follow-up, primary health care, psychosocial interventions, and administration of opiate treatments in a clinical setting. Psychosocial treatment includes medical and psychiatric follow-up, primary health care, psychosocial interventions, and, if necessary, administration of pharmacotherapy in a clinical setting.

\section{Outcomes}

The outcomes were as follows: (a) the AUDIT scores; (b) the number of glasses of alcohol per week (1 glass: $10 \mathrm{~g}$ of alcohol; wine $=100 \mathrm{ml}$; beer $=250 \mathrm{ml}$; spirits = $25 \mathrm{ml}$ ); and (c) frequency of alcohol use (consumption rate). These outcomes were assessed at baseline and then at months 3 and 9 .

\section{Randomization}

Two hundred and fifty-four patients met the study inclusion criteria and accepted the invitation to participate. Of this number, and after an AUDIT screening conducted by a physician or a nurse, 112 patients were subsequently randomly assigned to intervention or control groups in a 1:1 ratio. The randomization scheme was drawn by a statistician, who used the Web site [http://www.randomizer. org/]. A random permuted block method was used, with blocks of 4 patients. The sequence was concealed from all investigators with numbered opaque sealed envelopes prepared by the statistician and handed over to the physician in charge of the study.

\section{Analyses}

Statistical analysis was performed by using SPSS for Windows (version 18.0, IBM, Chicago, IL, USA). An initial exploratory analysis involved the calculation of proportions, means, and standard deviation to describe the baseline characteristics.

To analyze differences between participants who gave follow-up data and those who did not, we performed two logistic regressions. A binary dependent variable was generated, taking on a value of 0 if audit scores were missing at T3 and a value of 1 if audit scores were present. Type of drinkers (excessive drinkers vs. alcohol dependent) and treatment groups (treatment as usual vs. treatment as usual plus BI) served as independent variables. The same was done at T9. AUDIT internal consistency was explored by using the Cronbach $\alpha$ coefficient. This index varies between 0 and 1 and translates a greater degree of internal coherence if its value is close to 1 . It is generally accepted that the internal consistency of an instrument is satisfactory when the value of the coefficient is equal to or above 0.70 .
The evolution of AUDIT scores was analyzed by repeated measures analysis of variance (ANOVA), with treatment group (treatment as usual vs. treatment as usual plus BI), type of drinker (excessive drinker vs. alcohol dependent), and sex (male vs. female) as factors. The evolution of the quantity of alcohol consumed (number of glasses of alcohol per week) was also considered by ANOVA models, again with treatment group, type of drinker, and sex as factors. The variable that measured the quantity of alcohol consumed had to be log-transformed $\left[\mathrm{x}^{\prime}=\log (\mathrm{x}+1)\right]$ beforehand, with the aim of making the distribution less skewed; two unlikely values, one in each group (200 glasses/week for one participant of the control group and 196 glasses/week for another of the BI group, respectively) were not considered in the analysis. In these ANOVA models, main effects, factor $\times$ time and factor $\times$ factor $\times$ time interactions, were paid due attention.

The consumption rate was estimated by using the first item of the AUDIT questionnaire (How often do you have a drink containing alcohol? Never (0), Monthly or less (1), Two to four times a month (2), Two to three times per week (3), Four or more times a week (4)). The first question of the AUDIT explores the frequency of alcohol consumption during the last year (never, once a month, 2 to 4 times per month, 2 or 3 times per week, 4 times or more per week).

We considered the decrease of consumption between the study time periods as a success (coded 1 ) and an increase or no change as a failure (coded 0 ). This method results in three binary outcomes $(0,1)$ for measures at baseline (T0), month 3 (T3), and month 9 (T9). Nonparametric Cochran's $Q$ tests were carried out to assess whether the distribution of the values is the same for the three related dichotomous variables.

All analyses were done on a modified intention-to-treat basis. Missing data were handled by multiple imputation techniques in which scale variables were modeled with linear regression and categorical variables with logistic regression. Under the assumption that data are missing completely at random, pooled estimates were calculated and the complete data set could then be analyzed by standard methods. All statistical analyses were performed with a significant threshold of $\alpha=0.05$.

\section{Results}

Three hundred patients were contacted for inclusion. Among them, 32 declined study participation and 14 were not included due to their engagement in an alcohol-related treatment. Finally, 254 patients (mean age: 35 years; range: $18-56 ; 72.3 \%$ male) signed written informed consent, completed the first evaluation, and were included in the study (Figure 1; Table 1).

Some patients were treated for opiate dependence with methadone substitution (56.2\%) or diacethyl morphine 


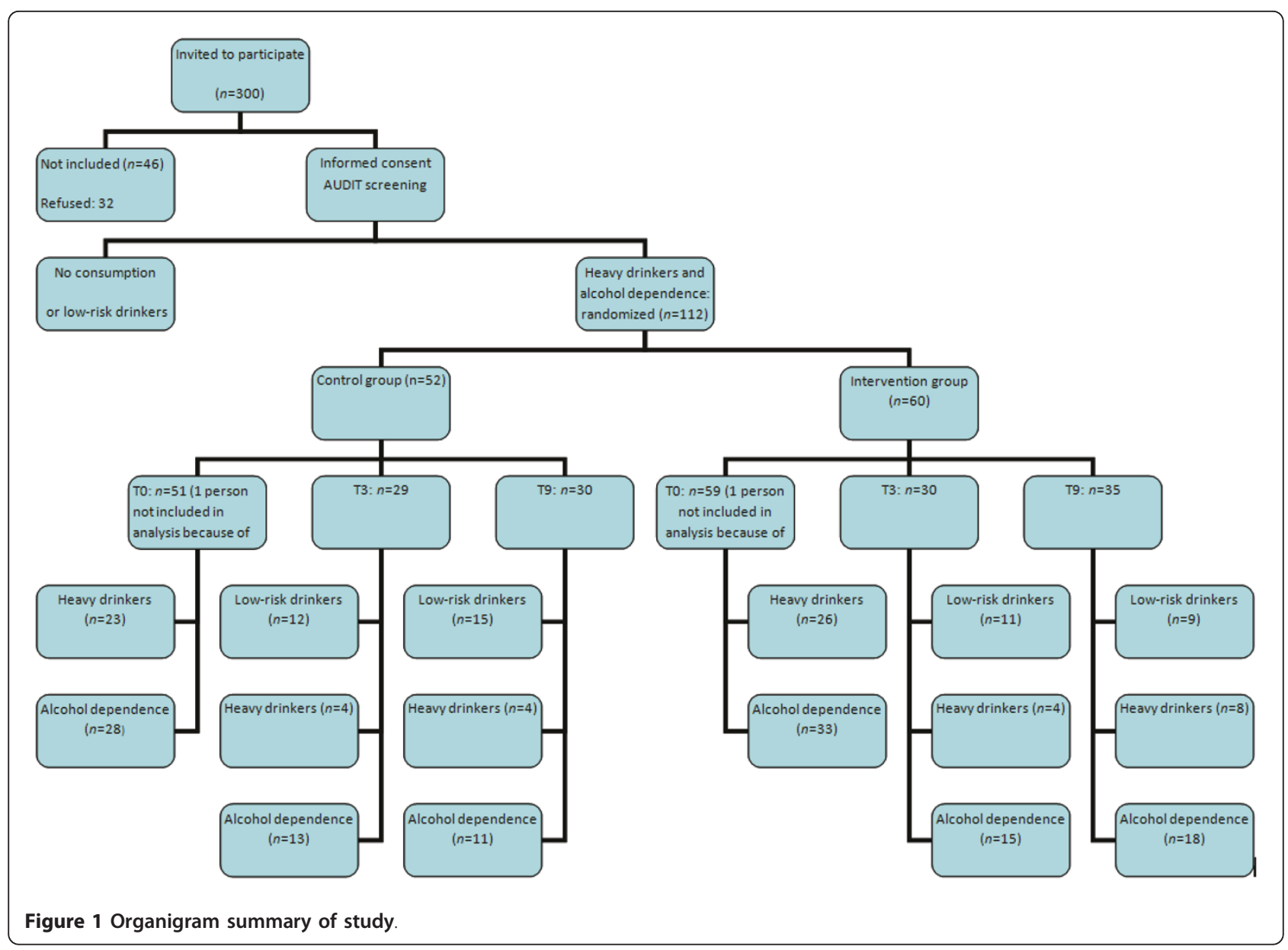

(heroin treatment; 12\%). Other patients had no opioid substitution and were treated for opiate or cocaine

Table 1 Baseline characteristics of the whole sample

\begin{tabular}{ll}
\hline & $\mathbf{N}=\mathbf{2 5 4}$ \\
\hline Age $[(M)(S D)]$ & $35(7.8)$ \\
AUDIT TO $[(M(S D)]$ & $8.8(9)$ \\
Alcohol consumption T0 (\%) & 55.5 \\
$\quad$ Low-risk drinkers & 19.7 \\
$\quad$ Heavy drinkers & 24.8 \\
$\quad$ Alcohol dependence & 72.3 \\
Men (\%) & \\
Treatment (\%) & 56.2 \\
$\quad$ Methadone & 12 \\
$\quad$ Diacethyl-morphine (heroin) & 31.7 \\
$\quad$ Patients without substitution & \\
Psychiatric disorder (\%) & 35.6 \\
$\quad$ Mood disorder & 34 \\
Personality disorder & 14.7 \\
$\quad$ Anxiety disorder & 9.4 \\
\hline Psychotic disorder
\end{tabular}

AUDIT = Alcohol Use Disorders Identification Test; T0 = baseline . dependence (31.7\%). Acceptance to participate in the study was similar (broad; wide) for both groups (patients with or without substitution). Most patients with cocaine dependence or with opiate dependence also had tobacco or cannabis dependence. Most patients had one or more concomitant psychiatric disorders (mood disorder, 35.6\%; personality disorder, 34\%; anxiety disorders, $14.7 \%$; psychotic disorders, 9.4\%). Logistic regressions showed that the type of drinker and treatment group did not explain the missingness of data. At T3, the odds ratio was 1.03 with confidence intervals of $[0.46 ; 2.29]$ for type of drinker and $1.10[0.50 ; 2.43]$ for treatment groups. At T9, the odds ratio was 0.78 with confidence intervals of [0.35; $1.75]$ for type of drinker and $1.22[0.55 ; 2.70]$ for treatment groups. Hence, these variables displayed no particular pattern, meaning that the data for excessive drinkers and for alcohol-dependent patients, as well as for the control group and the intervention group, were equally likely to be missing.

The AUDIT shows an excellent internal consistency in this population (Cronbach $\alpha=0.90$ ). According to AUDIT cutoffs, 142 patients (55.9\%) had no alcohol problems, whereas 112 (44.1\%) were considered problematic 
Table 2 Baseline characteristics of the control and intervention groups

\begin{tabular}{llll}
\hline & $\begin{array}{l}\text { Control Group } \\
(\boldsymbol{N}=\mathbf{5 2})\end{array}$ & $\begin{array}{l}\text { Intervention Group } \\
(\boldsymbol{N}=\mathbf{6 0})\end{array}$ & $\boldsymbol{p}$ Value \\
\hline Age $[(M(S D)]$ & $34.8(6.9)$ & $34.2(8.6)$ & 0.6 \\
AUDIT T0 $[(M(S D)]$ & $16.8(8.3)$ & $17(7.6)$ & 0.9 \\
Category of alcohol consumption: T0 \% & 0 & 0 \\
$\quad$ Low-risk drinkers & 44.2 & 43.3 & 0.8 \\
$\quad$ Heavy drinkers & 55.8 & 56.7 & 75 \\
$\quad$ Alcohol dependence & 71.2 & 40.7 & 0.6 \\
Male (\%) & 60.8 & 11.9 & 0.1 \\
Treatment (\%) & 9.8 & 47.5 & \\
$\quad$ Methadone & 29.4 & & \\
$\quad$ Diacethyl morphine (heroin) & & &
\end{tabular}

AUDIT = Alcohol Use Disorders Identification Test; T0 = baseline.

drinkers. At inclusion, among those with problematic alcohol consumption, $43.8 \%$ were classified as excessive drinkers and $56.2 \%$ as alcohol dependents.

These 112 persons were randomized to receive BI plus treatment as usual (intervention group) or treatment as usual (control group). Because of data-entry errors, however, data for 110 persons were considered in a modified intention-to-treat analysis. Of the BI group, $59.3 \%$ completed the last observation and of the control group, $58.8 \%$ completed it (Figure 1). No differences were observed between the two treatment groups at baseline (Table 2).

For AUDIT scores, repeated measures ANOVA shows a statistically significant overall time effect $(F(2,101)=$ 11.1 and $p<0.0005)$ and type of drinker $\times$ time interaction $(F(2,101)=13.8$ and $p<0.0005)$. The test of withinsubject contrasts shows a significant AUDIT scores difference, irrespective of the treatment groups, between T0 and T3 $(F(1,102)=16.6$ and $p<0.0005)$, but not between T3 and T9. This difference reflects a decrease of the average score (Table 3). The test of within-subject contrasts also shows that AUDIT scores for excessive drinkers and alcohol dependents depend upon time and that a significant difference exists between T0 and T3 $(F(1,102)=24.8$ and $p<0.0005)$. During this time interval, we observed an AUDIT score reduction for alcoholdependent patients and an increase for excessive drinkers (Table 4). As shown in Table 4, however, the mean AUDIT score for excessive drinkers remained lower than
13, the cutoff criteria for alcohol dependence. We did not observe treatment group $\times$ time nor sex $\times$ time interactions. However, there was a main effect for sex $(F(1,102)=$ 5.5 and $p=0.02)$ and for type of drinker $(F(1,102)=47.8$ and $p<0.0005)$, signifying that AUDIT scores depend on sex and type of drinker (Tables 4 and 5).

The ANOVA for the quantity of alcohol consumed, with treatment group, type of drinker, and sex as factors, shows an effect of time that is statistically significant $(F(2,101)=15.7$ and $p<.0005)$. The contrast values give a statistically significant difference toward a decrease between T0 and T3 $(F(1,102)=29.6$ and $p<.0005)$. No factor $\times$ time interactions were observed. Nevertheless, a main effect was observed for type of drinker $(F(1,102)=$ 9 and $p=.003)$, showing that a statistically significant difference exists between excessive drinkers and alcohol dependents for the overall number of alcoholic drinks consumed (Tables 4 and 6).

The main changes in alcohol consumption (AUDIT scores, number of drinks, and frequency) are observed at T3, but changes in frequency and number of drinks do not persist at T9. To check whether the rates of alcohol consumption (according to the first AUDIT question) differ across time for the intervention and control groups, we used the Cochran $\mathrm{Q}$ test. This test did not find a significant statistical distribution difference across time (Table 7), either for the patients benefitting from the BI $(Q=0.5$ and $p=0.6)$, or for the control group $(Q=1.1$ and $p=0.4)$.

Table 3 AUDIT scores and number of alcohol drinks per week

\begin{tabular}{llllllllll}
\hline & \multicolumn{3}{c}{ Control Group } & \multicolumn{3}{c}{ Intervention Group } & \multicolumn{3}{c}{ Control + Intervention } \\
\cline { 2 - 10 } & T0 & T3 & T9 & T0 & T3 & T9 & T0 & T3 & T9 \\
\hline AUDIT [M (SD)] & 16.6 & 14.8 & 12.3 & 16.9 & 14.9 & 13.8 & 16.8 & 14.9 & 13 \\
& $(8.2)$ & $(8.9)$ & $(8.6)$ & $(7.7)$ & $(7.2)$ & $(8.7)$ & $(7.9)$ & $(8)$ & $(8.6)$ \\
Number of drinks/week [(M (SD)] & 20.9 & 13 & 16.4 & 25 & 15.4 & 14.7 & 23.4 & 14.5 & 15.6 \\
& $(15)$ & $(19.5)$ & $(20.7)$ & $(19.6)$ & $(17.6)$ & $(17.5)$ & $(17.9)$ & $(18.3)$ & $(19)$ \\
\hline
\end{tabular}

AUDIT = Alcohol Use Disorders Identification Test; T0 $=$ baseline; $\mathrm{T} 3=$ month 3; $\mathrm{T} 9=$ month 9. 
Table 4 AUDIT scores and number of alcohol drinks per week in excessive drinkers and alcohol dependents

\begin{tabular}{lllllll}
\hline & \multicolumn{3}{c}{$\begin{array}{c}\text { Excessive } \\
\text { Drinkers }\end{array}$} & \multicolumn{3}{c}{$\begin{array}{c}\text { Alcohol } \\
\text { Dependents }\end{array}$} \\
\cline { 2 - 8 } & T0 & T3 & T9 & T0 & T3 & T9 \\
\hline Number of drinks per week & 17.1 & 14.2 & 10.8 & 34.5 & 24.8 & 24 \\
[(M (SD)] & $(12.4)$ & $(8.1)$ & $(8.8)$ & $(17.8$ & $(15.8)$ & $(19.6)$ \\
AUDIT [M (SD)] & 9.4 & 11.2 & 8 & 21.9 & 17.4 & 16.6 \\
& $(1.9)$ & $(6.6)$ & $(5.4)$ & $(6.2)$ & $(7.9)$ & $(8.7)$
\end{tabular}

AUDIT = Alcohol Use Disorders Identification Test; T0 = baseline; T3 = month 3; T9 = month 9

\section{Discussion}

In the present study, significant decreases in AUDIT scores were observed at T3 and T9 in both treatment groups, without gender differences, as previously found elsewhere $[14,18,20,31]$. In our study, gender differences were not linked to treatment effect but to a more general pattern of alcohol consumption. Similarly, a significant decrease in alcohol consumption was observed at T3. The main changes in alcohol consumption (AUDIT scores, number of drinks, and frequency) are observed at $\mathrm{T} 3$, but changes in frequency and number of drinks do not persist at T9. This is possibly due to a reduction of the intervention effect over time.

Of interest, these results are in accordance with other studies founding a significant decrease in the consumption of alcohol following BI $[14,15]$, including among a population of intravenous drug users [2]. Astonishingly, dependent subjects improved better than excessive drinkers in AUDIT scores between T0 and T3. This difference between types of drinker was not observed for the number of drinks consumed per week. In the present setting, BI did not have an additional effect in comparison with AUDIT screening. This is possibly due to a lower impact of BI in this target population $[20,21,32]$. BI has previously been found to be less efficient among alcohol dependents $[14,24]$. Furthermore, lack of differences between interventions may simply show that screening alcohol use with AUDIT and providing feedback about the score has a positive impact on alcohol-drinking behaviors [33]. This phenomenon has been evoked by different studies and could correspond to what Jenkins et al. call reactivity to assessment [34]. The results were also

Table 5 AUDIT scores (Mean (SD)) by group and sex

\begin{tabular}{llllllllll}
\hline & Control Group & \multicolumn{3}{c}{$\begin{array}{c}\text { Intervention } \\
\text { Group }\end{array}$} & \multicolumn{3}{c}{$\begin{array}{c}\text { Control + } \\
\text { Intervention }\end{array}$} \\
\cline { 2 - 10 } & T0 & T3 & T9 & T0 & T3 & T9 & T0 & T3 & T9 \\
\hline Men & 17.6 & 16.5 & 13.9 & 17.3 & 15.1 & 14.4 & 17.4 & 15.7 & 14.2 \\
& $(9)$ & $(8.7)$ & $(8.5)$ & $(7.9)$ & $(7)$ & $(9.3)$ & $(8.4)$ & $(7.8)$ & $(8.9)$ \\
Women & 14.2 & 10.7 & 8.5 & 16 & 14.3 & 12.2 & 15.1 & 12.5 & 10.3 \\
& $(5.4)$ & $(8.2)$ & $(7.8)$ & $(6.9)$ & $(8)$ & $(6.4)$ & $(6.2)$ & $(8.2)$ & $(7.2)$ \\
\hline
\end{tabular}

AUDIT = Alcohol Use Disorders Identification Test; T0 = baseline; $\mathrm{T} 3=$ month $3 ;$ T9 $=$ month 9 .
Table 6 Number of alcohol drinks per week by group and gender

\begin{tabular}{llllllllll}
\hline & \multicolumn{3}{c}{ Control Group } & \multicolumn{3}{c}{$\begin{array}{c}\text { Intervention } \\
\text { Group }\end{array}$} & \multicolumn{3}{c}{$\begin{array}{c}\text { Control + } \\
\text { Intervention }\end{array}$} \\
\cline { 2 - 10 } & T0 & T3 & T9 & T0 & T3 & T9 & T0 & T3 & T9 \\
\hline Men & 31 & 22.9 & 20.6 & 28.8 & 21 & 20.4 & 29.8 & 21.8 & 20.5 \\
& $(20)$ & $(16.4)$ & $(17.2)$ & $(17.6)$ & $(14)$ & $(20.6)$ & $(18.7)$ & $(15)$ & $(19)$ \\
Women & 22 & 14.8 & 12.3 & 19.7 & 18.5 & 15.1 & 20.8 & 16.7 & 13.7 \\
& $(13.4)$ & $(12)$ & $(11.3)$ & $(15.1)$ & $(9.8)$ & $(9.8)$ & $(14)$ & $(11)$ & $(10.5)$ \\
\hline
\end{tabular}

AUDIT = Alcohol Use Disorders Identification Test; T0 = baseline; T3 = month 3; $\mathrm{T} 9=$ month 9 .

possibly due to spontaneous adaptations of the naturalistic "treatment as usual" received by both groups following AUDIT screening or BI.

In this study, screening with the AUDIT, as well as the $\mathrm{BI}$, induced changes in alcohol consumption among heroin and cocaine users in treatment. This result possibly means that in an addiction clinic, both strategies were useful. In the absence of a naturalistic or waiting list group, we cannot fully exclude a spontaneous favorable evolution linked to time or to other concomitant factors such as treatment as usual. It is probable, however, that in the absence of a specific intervention targeting alcohol consumption, patients treated for opiate or cocaine addiction may not usually receive sufficient attention for alcohol misuse.

In fact, one of the limitations of the present study is the lack of data about naturalistic change during treatment as usual. Participation in the study was voluntary and all participants were selected by convenience sampling when they came to the Division of Substance Abuse for treatment. As there is a lack of studies that have evaluated the longitudinal effect of the intervention within this specific group of drug-addicted patients, no a priori sample size calculation had been undertaken. Indeed, the extreme heterogeneity of patient characteristics, health care, and study settings made it difficult to provide reliable effect size estimates for sample size calculation for continuous endpoints. If we had to take, for instance, an effect size of $30 \%$ and a correlation among the repeated observations of 0.4 , using the equation for sample size calculations given by Diggle et al. [35], with a power of 0.8 , would yield a minimum sample size of 82 persons in each arm. This estimate, if a plausible guess, shows that the current study sample size may have proven insufficient to reject the null hypothesis at the 0.05 level. Hence, the study may be underpowered and may have led to discarding the BI as a potentially useful treatment.

Nevertheless, because of the simplicity of the proposed interventions and the relatively important improvements observed (reduction in the number of drinks per week from 20.9 at T0 to 13 at T3 in the control group and from 25 at T0 to 15.4 at T3 in the intervention group), 
Table 7 Evolution of alcohol consumption by treatment group

\begin{tabular}{lllll}
\hline & Control Group & \multicolumn{2}{l}{ Intervention Group } \\
\cline { 2 - 5 } & T0-T3 & T3-T9 & T0-T3 & T3-T9 \\
\hline Increased or unchanged alcohol use: failure $(n)$ & 16 & 14 & 46 & 52 \\
Decreased alcohol use: success $(n)$ & 35 & 37 & 13 & 7 \\
\hline
\end{tabular}

AUDIT = Alcohol Use Disorders Identification Test; T0 = baseline; T3 = month 3; T9 = month 9.

systematic screening with AUDIT, followed by feedback on the score, and/or BI for alcohol misuse among outpatients treated for opiate or cocaine dependence will be promoted and investigated as having promising potential in this target group. The screening, followed by feedback on the problematic use of alcohol, is an interesting strategy to include in a population of heroin and cocaine users. New tools, such as the Alcohol, Smoking and Substance Involvement Screening Test (ASSIST) questionnaire, deserve to be evaluated in future research for screening the use of alcohol and other substances [36].

As previously found [1], another important result of the present study is the excellent internal consistency of AUDIT in a population of patients treated for opiate or cocaine dependence. Using this instrument, we found a $44 \%$ rate for problematic alcohol consumption (excessive drinking and dependence), confirming results of other studies on similar populations $[2,3]$.

\section{Acknowledgements}

We thank the staff (nurses, psychologists, social workers, and psychiatrists) and the patients who participated in this research. We also thank Pascal Gache, MD, for his collaboration in brief intervention training.

\section{Authors' contributions}

NF designed the study. AC conducted the statistical analyses. NF, AC, and YK wrote the first draft and compiled the co-authors' suggestions. All authors participated in the drafting of the manuscript and approved the final version.

\section{Competing interests}

The authors declare that they have no competing interests.

Received: 6 January 2011 Accepted: 17 August 2011

Published: 17 August 2011

\section{References}

1. Skipsey K, Burleson JA, Kranzler HR: Utility of the AUDIT for identification of hazardous or harmful drinking in drug-dependent patients. Drug Alcohol Depend 1997, 45:157-163.

2. Stein MD, Charuvastra A, Maksad J, Anderson BJ: A randomized trial of a brief alcohol intervention for needle exchangers (BRAINE). Addiction 2002, 97:691-700.

3. Nyamathi A, Cohen A, Marfisee M, Shoptaw S, Greengold B, de Castro V, George D, Leake B: Correlates of alcohol use among methadonemaintained adults. Drug Alcohol Depend 2009, 101:124-127.

4. Maremmani I, Pani PP, Mellini A, Pacini M, Marini G, Lovrecic M, Perugi G, Shinderman M: Alcohol and cocaine use and abuse among opioid addicts engaged in a methadone maintenance treatment program. J Addict Dis 2007, 26:61-70.

5. Srivastava A, Kahan M, Ross S: The effect of methadone maintenance treatment on alcohol consumption: a systematic review. J Subst Abuse Treat 2008, 34:215-223.
6. Hickman M, Lingford-Hughes A, Bailey C, Macleod J, Nutt D, Henderson G: Does alcohol increase the risk of overdose death: the need for a translational approach. Addiction 2008, 103:1060-1062.

7. Warner-Smith M, Darke S, Lynskey M, Hall W: Heroin overdose: causes and consequences. Addiction 2001, 96:1113-1125.

8. Hickman M, Carrivick S, Paterson S, Hunt N, Zador D, Cusick L, Henry s: London audit of drug-related overdose deaths: characteristics and typology, and implications for prevention and monitoring. Addiction 2007, 102:317-323

9. Bryant WK, Galea S, Tracy M, Markham Piper T, Tardiff KJ, Vlahov D: Overdose deaths attributed to methadone and heroin in New York City, 1990-1998. Addiction 2004, 99:846-854.

10. Senbanjo R, Wolff $\mathrm{K}$, Marshall J: Excessive alcohol consumption is associated with reduced quality of life among methadone patients. Addiction 2007, 102:257-263.

11. Arasteh K, Des Jarlais DC, Perlis TE: Alcohol and HIV sexual risk behaviors among injection drug users. Drug Alcohol Depend 2008, 95:54-61.

12. Lacoste J, Pedrera-Melgire M, Charles-Nicolas A, Ballon N: [Cocaine and alcohol: a risky association]. Presse Med 2010, 39:291-302.

13. Pennings EJ, Leccese AP, Wolff FA: Effects of concurrent use of alcohol and cocaine. Addiction 2002, 97(7):773-783.

14. Bien TH, Miller WR, Tonigan JS: Brief interventions for alcohol problems: a review. Addiction 1993, 88:315-335.

15. Wilk Al, Jensen NM, Havighurst TC: Meta-analysis of randomized control trials addressing brief interventions in heavy alcohol drinkers. J Gen Intern Med 1997, 12:274-283.

16. Fleming MF, Barry KL, Manwell LB, Johnson K, London R: Brief physician advice for problem alcohol drinkers: a randomized controlled trial in community-based primary care practices. JAMA 1997, 277:1039-1045.

17. Havard A, Shakeshaft A, Sanson-Fisher R: Systematic review and metaanalyses of strategies targeting alcohol problems in emergency departments: interventions reduce alcohol-related injuries. Addiction 2008, 103:368-376, discussion 377-368

18. Kaner EF, Dickinson HO, Beyer F, Pienaar E, Schlesinger C, Campbell F, Saunders JB, Burnand B, Heather N: The effectiveness of brief alcohol interventions in primary care settings: a systematic review. Drug Alcohol Rev 2009, 28:301-323.

19. Tait RJ, Hulse GK, Robertson SI: Effectiveness of a brief-intervention and continuity of care in enhancing attendance for treatment by adolescent substance users. Drug Alcohol Depend 2004, 74:289-296.

20. Bertholet N, Daeppen JB, Wietlisbach V, Fleming M, Burnand B: Reduction of alcohol consumption by brief alcohol intervention in primary care: systematic review and meta-analysis. Archives Intern Med 2005, 165:986-995.

21. Grothues JM, Bischof G, Reinhardt S, Meyer C, John U, Rumpf HJ: Effectiveness of brief alcohol interventions for general practice patients with problematic drinking behavior and comorbid anxiety or depressive disorders. Drug Alcohol Depend 2008, 94:214-220.

22. Daeppen JB, Gaume J, Bady P, Yersin B, Calmes JM, Givel JC, Gmel G: Brief alcohol intervention and alcohol assessment do not influence alcohol use in injured patients treated in the emergency department: a randomized controlled clinical trial. Addiction 2007, 102:1224-1233.

23. Freyer-Adam J, Coder B, Baumeister SE, Bischof G, Riedel J, Paatsch K, Wedler B, Rumpf HJ, John U, Hapke U: Brief alcohol intervention for general hospital inpatients: a randomized controlled trial. Drug Alcohol Depend 2008, 93:233-243

24. Madras BK, Compton WM, Avula D, Stegbauer T, Stein JB, Clark HW: Screening, brief interventions, referral to treatment (SBIRT) for illicit drug and alcohol use at multiple healthcare sites: comparison at intake and 6 months later. Drug Alcohol Depend 2009, 99:280-295.

25. Babor TF, Higgins-Biddle JC: Brief Intervention for Hazardous and Harmful Drinking: A Manual for Use in Primary Care Geneva: World Health 
Organization (WHO), Department of Mental Health and Substance Dependence; 2001

26. Bohn MJ, Babor TF, Kranzler HR: The Alcohol Use Disorders Identification Test (AUDIT): validation of a screening instrument for use in medical settings. J Stud Alcohol 1995, 56:423-432.

27. Allen JP, Litten RZ, Fertig JB, Babor T: A review of research on the Alcohol Use Disorders Identification Test (AUDIT). Alcohol Clin Exp Res 1997, 21:613-619.

28. Reinert DF, Allen JP: The Alcohol Use Disorders Identification Test: an update of research findings. Alcohol Clin Exp Res 2007, 31:185-199.

29. Gache P, Michaud P, Landry U, Accietto C, Arfaoui S, Wenger O,

Daeppen JB: The Alcohol Use Disorders Identification Test (AUDIT) as a screening tool for excessive drinking in primary care: reliability and validity of a French version. Alcohol Clin Exp Res 2005, 29:2001-2007.

30. World Health Organization (WHO): Classification Internationale des troubles mentaux et des troubles du comportement, Critères diagnostiques Masson edn. Paris; 1994.

31. Ballesteros J, Gonzalez-Pinto A, Querejeta I, Arino J: Brief interventions for hazardous drinkers delivered in primary care are equally effective in men and women. Addiction 2004, 99:103-108.

32. Gossop M, Stewart D, Marsden J: Effectiveness of drug and alcohol counselling during methadone treatment: content, frequency, and duration of counselling and association with substance use outcomes. Addiction 2006, 101:404-412.

33. McCambridge J, Day M: Randomized controlled trial of the effects of completing the Alcohol Use Disorders Identification Test questionnaire on self-reported hazardous drinking. Addiction 2008, 103:241-248.

34. Jenkins RJ, McAlaney J, McCambridge J: Change over time in alcohol consumption in control groups in brief intervention studies: systematic review and meta-regression study. Drug Alcohol Depend 2009, 100:107-114

35. Diggle P, Kung-Yee L, Zeger Z: Analysis of Longitudinal Data New York: Oxford University Press; 1994.

36. Khan R, Chatton A, Nallet A, Broers B, Thorens G, Achab-Arigo S, Poznyak V, Fleischmann A, Khazaal Y, Zullino D: Validation of the French Version of the Alcohol, Smoking and Substance Involvement Screening Test (ASSIST). Eur Addict Res 2011, 17:190-197.

doi:10.1186/1747-597X-6-22

Cite this article as: Feldman et al:: Alcohol-related brief intervention in patients treated for opiate or cocaine dependence: a randomized controlled study. Substance Abuse Treatment, Prevention, and Policy 2011 6:22.

\section{Submit your next manuscript to BioMed Central and take full advantage of:}

- Convenient online submission

- Thorough peer review

- No space constraints or color figure charges

- Immediate publication on acceptance

- Inclusion in PubMed, CAS, Scopus and Google Scholar

- Research which is freely available for redistribution

Submit your manuscript at www.biomedcentral.com/submit
Biomed Central 